\title{
AVALIAÇÃO DA PRODUÇÃO DE BIOSSURFACTANTES POR DIFERENTES LINHAGENS DE Bacillus sp. ISOLADAS DE SOLOS DE MANGUEZAL
}

\author{
D.W.F. OLIVEIRA ${ }^{1}$,D.P. BEZERRA ${ }^{2}$, I. W. L. DE FRANÇA ${ }^{1}$, B. N. SANTOS ${ }^{1}$, \\ V.M.M. MELO ${ }^{3}$, L.R.B. GONÇALVES ${ }^{1}$ \\ ${ }^{1}$ Universidade Federal do Ceará, Departamento de Engenharia Química \\ ${ }^{2}$ Universidade Federal do Ceará, Departamento de Engenharia \\ de Alimentos \\ ${ }^{3}$ Universidade Federal do Ceará, Departamento de Biologia \\ E-mail para contato: darlannefreitas@gmail.com
}

\begin{abstract}
RESUMO - Biossurfatantes são bioprodutos de origem microbiana amplamente utilizados na agricultura, produção de cosméticos, alimentos, produtos farmacêuticos, indústrias ambientais e petroquímica. Microganismos do gênero Bacillus são considerados um grupo adequado para a síntese industrial de biossurfactantes. O presente trabalho visou produzir surfactina, um lipopeptídeo, considerado um dos mais eficazes biossurfactantes, com grande poder de reduzir a tensão superficial da água e tensão interfacial de sistemas água - óleo. Estudou-se a produção de biossurfactantes por distintas linhagens de Bacillus sp. denominadas Jag248 e Jag249, em diferentes meios de cultivo, isoladas de solo de manguezal pertencentes a coleção de bactérias do Laboratório de Microbiologia e Imunologia da Universidade Federal do Ceará. Em testes preliminares com Jag248, obteve-se concentração de surfactina e de biomassa de até 161,0mg.L ${ }^{1}$ e $1,5 \mathrm{~g} . \mathrm{L}^{-1}$, respectivamente e capaz de reduzir tensão superficial para até $29,0 \mathrm{mN} / \mathrm{m}$.
\end{abstract}

\section{INTRODUÇÃO}

Biossurfactantes são compostos ativos de superfície produzidos por microorganismos. Existem muitos tipos de biossurfactantes com base em sua natureza química, tais como glicolipídeos, lipopolissacarídeos, oligossacarídeos, e lipopeptídeos foram relatados para ser produzido por diversos gêneros de bactérias (Banat et al., 2000, Banat et al., 2010; Franzetti et al., 2010). Apresentam diversas vantagens em relação aos surfactantes sintéticos, dentre elas pode-se destacar sua baixa toxicidade, alta biodegradabilidade, boa estabilidade frente a amplas faixas de temperatura, $\mathrm{pH}$ e sal, apresentando-se como um potencial produto para aplicações em proteção em proteção e gestão ambiental, recuperação de petróleo bruto, bem como agente como antimicrobiano (Abouseoud et al., 2008, Banat et al., 2000).

Os lipopeptídeos representam o segundo maior grupo de biossurfactantes de origem microbiana e são sintetizados por uma ampla gama de gêneros de microrganismos, incluindo Pseudomonas e Bacillus. Lipopeptídeos produzidos por bactérias do gênero Bacillus em particular, são os mais conhecidos, em especial a surfactina (Perfumo et al., 2010). 


\section{9 a 22 de outubro de 2014 \\ Florianópolis/SC}

O presente trabalho visou avaliar a produção de biossurfactante por distintas linhagens de Bacillus sp. denominadas Jag248 e Jag249, isoladas de solo de manguezal pertencentes a coleção de bactérias do Laboratório de Microbiologia e Imunologia da Universidade Federal do Ceará, em diferentes meios de cultivo.

\section{MATERIAIS E MÉTODOS}

Microrganismo: A manutenção e repique das culturas de Bacillus sp. Jag248 e Jag249, foram feitas em placas petri contendo meio APGE, compostos por peptona $(5,0 \mathrm{~g} / \mathrm{L})$, glicose $(5,0$ $\mathrm{g} / \mathrm{L})$, extrato de levedura $(2,5 \mathrm{~g} / \mathrm{L})$ e ágar $(15,0 \mathrm{~g} / \mathrm{L})$, esterilizados em autoclave a $121^{\circ} \mathrm{C}$ por 15 minutos. As placas APGE repicadas foram incubadas em estufa bacteriológica a $30^{\circ} \mathrm{C}$ por 24 horas para obtenção da cultura para realização dos ensaios fermentativos.

Inóculo: $\mathrm{O}$ meio de propagação do inóculo segue a mesma composição do meio utilizado para produção, tendo como fonte de carbono $\pm 20,0 \mathrm{~g} / \mathrm{L}$ de açúcares redutores totais (ART), ao utilizar suco de caju clarificado ou $10,0 \mathrm{~g} / \mathrm{L}$ de glicose em meio mineral com reativos padrão analítico e $1,0 \mathrm{~g} / \mathrm{L}$ de $\left(\mathrm{NH}_{4}\right)_{2} \mathrm{SO}_{4}$ como fonte de nitrogênio, esterilizados a $110^{\circ} \mathrm{C}$ por 10 minutos. Três alçadas da cultura na fase exponencial de crescimento foram transferidas para frascos de erlenmeyer de $250 \mathrm{~mL}$ contendo $50 \mathrm{~mL}$ meio de propagação do inóculo, incubado $180 \mathrm{rpm}, 30^{\circ} \mathrm{C}$ por 24 horas em agitador rotatório (Shaker Tecnal TE-480). O inóculo foi ajustado para uma faixa de 0,1 a 0,2 em espectrofotômetro a $600 \mathrm{~nm}$ e posteriormente adicionado ao meio de cultivo na proporção de $10 \% \mathrm{v} / \mathrm{v}$ de inóculo. A densidade ótica do inóculo foi acompanhada em espectrofotômetro (Genesys, série 20) a $600 \mathrm{~nm}$.

Meios de cultivo: estudaram-se diferentes meios de cultivo para ambas as cepas, como: (A) suco de caju clarificado $+\left(\mathrm{NH}_{4}\right)_{2} \mathrm{SO}_{4}+$ Extrato de Levedura; (B) suco de caju clarificado + (NH4)2SO4 $+\mathrm{Na}_{2} \mathrm{HPO}_{4}$; (C) suco de caju clarificado $+\left(\mathrm{NH}_{4}\right)_{2} \mathrm{SO}_{4}+\mathrm{KH}_{2} \mathrm{PO}_{4}$; (D) suco de caju clarificado $+\left(\mathrm{NH}_{4}\right)_{2} \mathrm{SO}_{4}+\mathrm{NaCl} ;(\mathrm{E})$ suco de caju clarificado $+\left(\mathrm{NH}_{4}\right)_{2} \mathrm{SO}_{4}+\mathrm{MgSO}_{4} \cdot 7 \mathrm{H}_{2} \mathrm{O} ;(\mathrm{F})$ Meio Mineral + suco de caju clarificado + Solução de Micronutrientes; (G) Meio Mineral + Solução de Micronutrientes; (H) Meio Mineral. O meio mineral e a solução de micronutrientes são de acordo com Móran et al.,(2000), modificando a concentração de $\mathrm{NaCl}$ de 27 g/L para 2,7 $\mathrm{g} / \mathrm{L}$.

Condução dos ensaios: Os experimentos foram realizados em agitador rotatório (Shaker Tecnal TE-480) por 72 horas em duplicata. Amostras foram retiradas nos intervalos de tempo de zero, 3, 6, 8, 20, 22, 24, 32, 48 e 72 horas e analisadas posteriormente. As amostras foram centrifugadas por 15 minutos a $10.000 \mathrm{~g}, 4^{\circ} \mathrm{C}$ e o sobrenadante livre de células, submetido às análises. Ajustou-se o pH para 7,0 antes da centrifugação para remoção das células, a fim de evitar perdas da surfactina devido a sua precipitação em pH ácido.

Análises realizadas: as medidas de tensão superficial foram realizadas em tensiômetro Kruss pelo método de Du Nöuy (Costa et al., 2006). O índice de emulsificação foi determinado de acordo com Cooper e Goldenberg (1987) e Makkar e Cameotra (1997) com pequenas modificações: 2,0 mL do meio de cultura fermentado livre de células foram colocados em tubo de 
ensaio, com fundo chato e adicionou-se o mesmo volume de diferentes fontes hidrofóbicas (querosene, n-hexadecano e óleo de soja) para avaliar o poder de emulsificação e estabilidade da surfactina produzida. A concentração de surfactina foi determinada por Cromatografia Líquida de Alta Eficiência (CLAE), acoplado com detector UV (Waters, modelo 2487) e equipado com a coluna de fase reversa Symmetry C18 (150 x 4,6 mm, $5 \mu \mathrm{m}$, Waters, Irlanda) conforme descrito em Oliveira, 2010. O consumo do substrato foi determinado por Cromatografia Líquida de Alta Eficiência (CLAE), utilizando cromatógrafo Waters (Modelo 2414) acoplado a detector de índice de refração (célula a $\left.40^{\circ} \mathrm{C}\right)$, coluna Supelcogel C610H $(30 \mathrm{~cm}$ x 7,8 mm) e pré-coluna $(5 \mathrm{~cm}$ x 4,6 mm) da Sigma Aldrich, (Oliveira et al., 2013).

\section{RESULTADOS E DISCUSSÕES}

\subsection{AVALIAÇÃo dO POTENCIAL DE PRODUÇÃO DE BIOSSURFACTANTES POR Bacillus sp. Jag249}

Realizaram-se três ensaios distintos com o microrganismo Bacillus sp. Jag249, utilizando diferentes meios de cultivo.

Bacillus sp. Jag249 em Meio Mineral + Solução de Micronutrientes, sob rotação de 180 rpm, temperatura $30^{\circ} \mathrm{C}$ e $\mathrm{pH} 7,0$ por 72 horas: para essas condições estudadas, pode-se observar na Figura 1A que obteve-se concentração celular de 5,26 \pm 1,61 g/L em 72 horas, com redução do $\mathrm{pH}$ para até 4,99 $\pm 0,04$. Não houve redução da tensão superficial, apresentando-se acima de 49,5 dina/cm, de acordo com a Figura 1B.
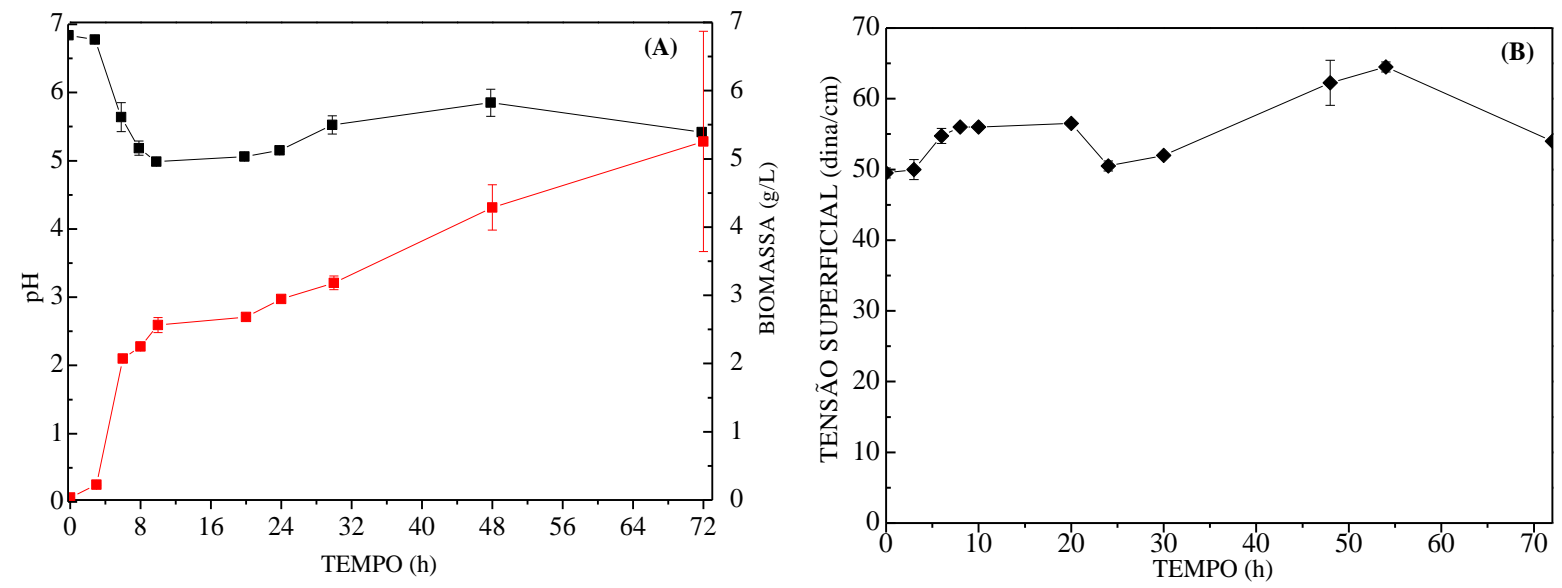

Figura 1 - (A) Perfil do crescimento celular (biomassa) e pH em função do tempo para Bacillus sp. Jag249, em Meio Mineral + Solução de Micronutrientes, sob rotação de $180 \mathrm{rpm}$, temperatura $30^{\circ} \mathrm{C}$ e pH 7,0. (घ) Biomassa, (匹) pH; (B) Redução da Tensão superficial em função do tempo $(\diamond)$.

Bacillus sp. Jag249 em Meio Mineral + Solução de Micronutrientes, sob rotação de 150 rpm, temperatura $30^{\circ} \mathrm{C}$ e pH 7,0 por 72 horas: variando-se a agitação, verificou-se concentração de biomassa de 4,92 \pm 0,79 $\mathrm{g} / \mathrm{L}$ em 30 horas de ensaio, mantendo-se na fase estacionária pelas 


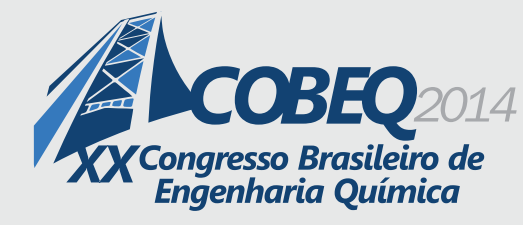

19 a 22 de outubro de 2014
Florianópolis/SC

horas seguintes. $\mathrm{O}$ pH foi reduzido a 4,70 $\pm 0,05$ em 24 horas de fermentação (Figura 2A). Não foi observada uma redução na tensão superficial, ficando acima de 53,00 $\pm 0,0 \mathrm{dina} / \mathrm{cm}$ e permanecendo nessa faixa no decorrer da fermentação, observado na Figura 2B.
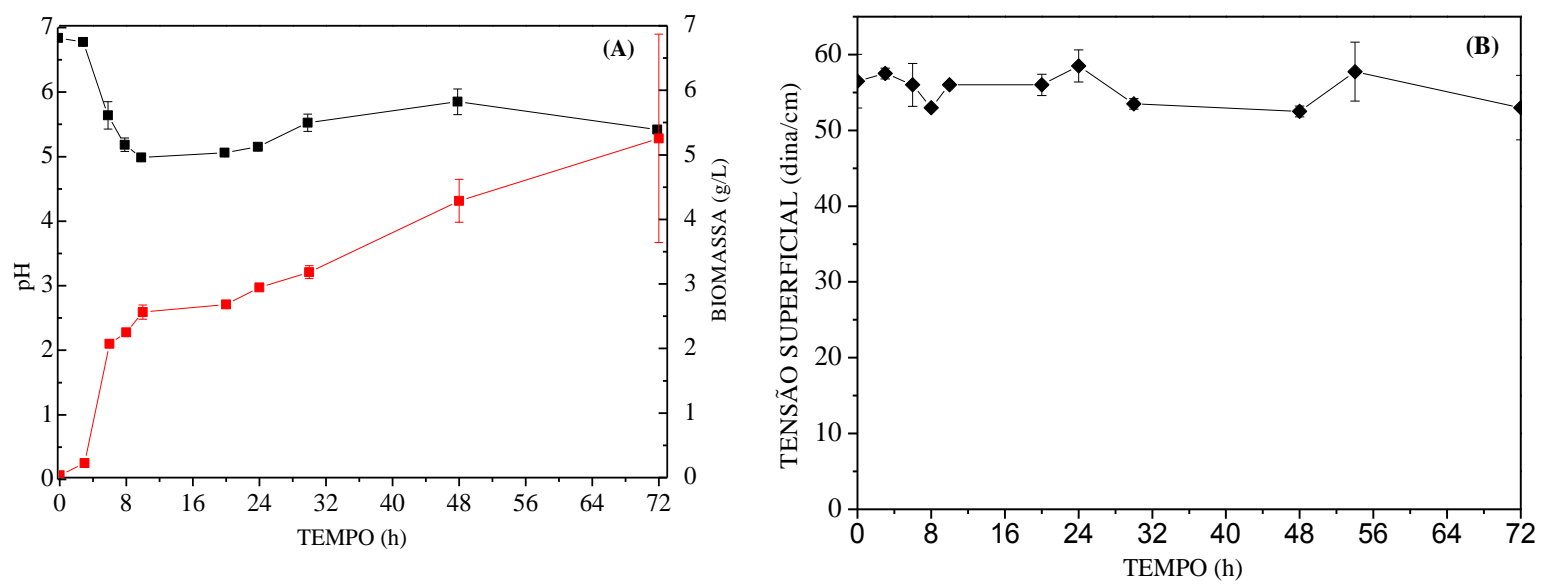

Figura 2 - (A) Perfil do crescimento celular (biomassa) e pH em função do tempo para Bacillus sp. Jag249, em Meio Mineral + Solução de Micronutrientes, sob rotação de $150 \mathrm{rpm}, 30^{\circ} \mathrm{C}$ e pH 7,0. (घ) Biomassa, (घ) pH; (B) Redução da Tensão superficial em função do tempo (•).

Ensaios variando meios de cultivo: utilizou-se os meios de cultivo para produção de biossurfactantes por Bacillus sp. Jag249 identificados por (A) suco de caju clarificado ( $\pm 20,0 \mathrm{~g} / \mathrm{L}$ $\mathrm{ART})+\left(\mathrm{NH}_{4}\right)_{2} \mathrm{SO}_{4}(1,0 \mathrm{~g} / \mathrm{L})$ + Extrato de Levedura $(5,0 \mathrm{~g} / \mathrm{L}) ;(\mathrm{B})$ suco de caju clarificado $( \pm$ $20,0 \mathrm{~g} / \mathrm{L} \mathrm{ART})+\left(\mathrm{NH}_{4}\right)_{2} \mathrm{SO}_{4}(1,0 \mathrm{~g} / \mathrm{L})+\mathrm{Na}_{2} \mathrm{HPO}_{4}(6,0 \mathrm{~g} / \mathrm{L}) ;(\mathrm{C})$ suco de caju clarificado $( \pm 20,0$ $\mathrm{g} / \mathrm{L} \mathrm{ART})+\left(\mathrm{NH}_{4}\right)_{2} \mathrm{SO}_{4}(1,0 \mathrm{~g} / \mathrm{L})+\mathrm{KH}_{2} \mathrm{PO}_{4}(3,0 \mathrm{~g} / \mathrm{L}) ;(\mathrm{D})$ suco de caju clarificado $( \pm 20,0 \mathrm{~g} / \mathrm{L}$ $\mathrm{ART})+\left(\mathrm{NH}_{4}\right)_{2} \mathrm{SO}_{4}(1,0 \mathrm{~g} / \mathrm{L})+\mathrm{NaCl}(2,7 \mathrm{~g} / \mathrm{L}) ;(\mathrm{E})$ suco de caju clarificado $( \pm 20,0 \mathrm{~g} / \mathrm{L}$ ART $)+$ $\left(\mathrm{NH}_{4}\right)_{2} \mathrm{SO}_{4}(1,0 \mathrm{~g} / \mathrm{L})+\mathrm{MgSO}_{4} \cdot 7 \mathrm{H}_{2} \mathrm{O}(0,6 \mathrm{~g} / \mathrm{L})$; (F) Meio Mineral + suco de caju clarificado ( \pm 20,0 g/L ART) + Solução de Micronutrientes; (G) Meio Mineral + Solução de Micronutrientes; (H) Meio Mineral. Os ensaios foram conduzidos em duplicata, em agitador rotarório, a $180 \mathrm{rpm}$, $30^{\circ} \mathrm{C}$ e pH 7,0. A Tabela 1 apresenta os resultados obtidos referentes ao crescimento celular (biomassa), pH e tensão superficial em função do tempo. Verificou-se no ensaio em meio de cultivo (A) concentração de biomassa de 4,56 \pm 0,04 g/L após 48 horas de fermentação, o $\mathrm{pH}$ apresentou-se inferior a 6,0. Em meio de cultivo (B), (C), (D) e (E) obteve-se concentração celular de $0,35 \pm 0,00 \mathrm{~g} / \mathrm{L}, 0,46 \pm 0,1 \mathrm{~g} / \mathrm{L}, 1,10 \pm 0,02 \mathrm{~g} / \mathrm{L}$ e $1,48 \pm 0,24 \mathrm{~g} / \mathrm{L}$ respectivamente, após 48 horas de ensaio, demonstrando baixo crescimento celular ao compará-lo com os outros ensaios realizados. $\mathrm{O}$ pH manteve-se superior a 6,0 nos ensaios (B), (C), (D) e (E). Nas condições do meio de cultivo $(\mathrm{F})$ verificou-se concentração de biomassa 2,67 $\pm 0,15 \mathrm{~g} / \mathrm{L}$, o pH apresentouse inferior a 6,0. Para os ensaios $(\mathrm{G})$ e $(\mathrm{H})$ verificou-se concentração de biomassa de 3,21 $\pm 0,19$ $\mathrm{g} / \mathrm{L}$ e 2,85 \pm 0,19 g/L, respectivamente, após 48 horas de fermentação. Observou-se pH maior que 6,0 .

Observa-se ainda na Tabela 1 que não ocorreu redução da tensão superficial nos ensaios realizados utilizando Bacillus sp. Jag249. 
Tabela 1 - Resultados obtidos de concentração celular (Biomassa), pH e tensão superficial (TS) em função do tempo para os ensaios realizados utilizando Bacillus sp. Jag249 variando a composição dos meios de cultivo.

\begin{tabular}{|c|c|c|c|}
\hline AMOSTRA & BIOMASSA $(\mathrm{g} / \mathrm{L})$ & $\mathrm{pH}$ & TS $(\mathrm{dina} / \mathrm{cm})$ \\
\hline A - 0 h & 0,03 & 6,63 & $53,5 \pm 0,00$ \\
$\mathrm{~A}-48 \mathrm{~h}$ & $4,56 \pm 0,04$ & $4,625 \pm 0,21$ & $55,52 \pm 5,65$ \\
\hline B - 0 h & 0,03 & 6,94 & $58,0 \pm 0,00$ \\
B - 48 h & $0,35 \pm 0,00$ & $6,695 \pm 0,05$ & $54,0 \pm 0,00$ \\
\hline C - 0 h & 0,03 & 6,55 & $61 \pm 0,00$ \\
C - 48 h & $0,46 \pm 0,02$ & $6,255 \pm 0,02$ & $61,5 \pm 0,55$ \\
\hline D - 0 h & 0,03 & 6,22 & $57,0 \pm 0,00$ \\
D - 48 h & $1,10 \pm 0,02$ & $6,465 \pm 0,05$ & $52,55 \pm 0,51$ \\
\hline E - 0 h & 0,04 & 5,89 & $64,0 \pm 0,00$ \\
E - 48 h & $1,48 \pm 0,24$ & $6,77 \pm 0,16$ & $55,8 \pm 1,98$ \\
\hline F - 0 h & 0,03 & 6,15 & $55,0 \pm 0,00$ \\
F- 48 h & $2,67 \pm 0,15$ & $6,825 \pm 0,01$ & $53,5 \pm 1,64$ \\
\hline G - 0 h & 0,04 & 6,57 & $50,0 \pm 0,00$ \\
G - 48 h & $3,21 \pm 0,19$ & $6,065 \pm 0,02$ & $52,5 \pm 2,74$ \\
\hline H - 0 h & 0,03 & 6,65 & $53,0 \pm 0,00$ \\
H - 48 h & $2,85 \pm 0,19$ & $7,055 \pm 0,05$ & $62,0 \pm 2,19$ \\
\hline
\end{tabular}

Um dos critérios utilizados para selecionar microrganismos produtores de biossurfactante é a habilidade em reduzir a tensão superficial abaixo de 40 dina/cm (Pinto, 2009). De acordo com os resultados obtidos, o microrganismo Bacillus sp. Jag249 não foi capaz de reduzir a tensão superficial do meio em nenhuma das condições avaliadas, logo não produziu biossurfactante. Barreto (2011), em estudos com essa cepa, obteve bons resultados de tensão superficial, de 29,4 \pm 1,4 dina/cm, apresentando-se potencial produtor. A cepa provavelmente sofreu mutação e perdeu sua capacidade de produção. Com isso era inviável dar continuidade as demais análises, visto que não houve redução de tensão superficial. Seguiu-se então os ensaios com a cepa Bacillus sp. Jag248, a fim de encontrar um microrganismo produtor de biossurfactante.

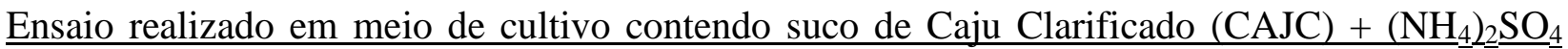
com microrganismo Bacillus subtilis Jag248: de acordo com a Figura 3(A), observa-se maior concentração de biomassa em torno de 1,00 \pm 0,04 $\mathrm{g} / \mathrm{L}$ após 30 horas de fermentação, uma crescente produção de biossurfactantes no decorrer das 72 horas chegando a concentração de $26,98 \pm 0,01 \mathrm{mg} / \mathrm{L}$ de surfactina. Ocorreu o consumo dos açúcares redutores totais (ART) mostrando que o microorganismo tem preferência por glicose e o pH manteve-se acima de 6,0. 

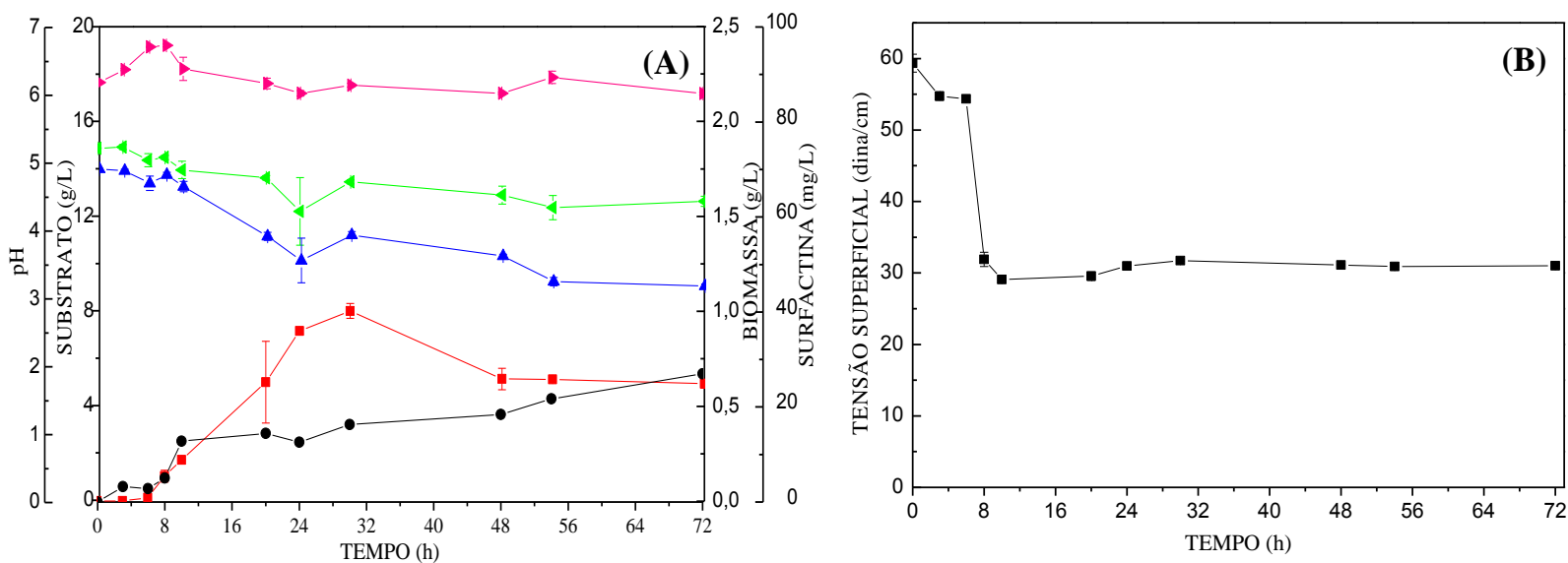

Figura 3 - (A) Perfil do crescimento celular (biomassa), consumo de substrato, produção de surfactina e pH em função do tempo para Bacillus subtilis Jag248, sob rotação de 180 rpm, temperatura de $30^{\circ} \mathrm{C}$ em Meio contendo Suco de Caju Clarificado (CAJC) e $\left(\mathrm{NH}_{4}\right)_{2} \mathrm{SO}_{4}:(\square)$

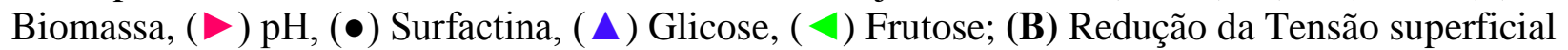

(a) em função do tempo para Bacillus subtilis Jag248, em meio contendo Suco de Caju Clarificado (CAJC) e $\left(\mathrm{NH}_{4}\right)_{2} \mathrm{SO}_{4}$.

Observou-se redução da tensão superficial do meio de cultivo livre de células, com valores de 29,10 \pm 0,12 dina/cm após 10 horas de ensaio e manteve-se nessa faixa até 72 horas, conforme mostra Figura 3(B).

A avaliação da capacidade emulsionante do biossurfactante produzido por Bacillus subtilis Jag248 pode ser observada na Tabela 2.

Tabela 2 - Resultados obtidos de Índice de Emulsificação para o ensaio realizado utilizando Bacillus subtilis Jag248 em Meio contendo Suco de Caju Clarificado (CAJC) e $\left(\mathrm{NH}_{4}\right)_{2} \mathrm{SO}_{4}$.

\begin{tabular}{c|c|c|c}
\hline AMOSTRA & ÓLEO DE SOJA & QUEROSENE & N-HEXADECANO \\
\hline $30 \mathrm{~h}$ & $\mathrm{NF}$ & $56,86 \pm 3,90$ & $36,28 \pm 23,03$ \\
\hline $48 \mathrm{~h}$ & $21,30 \pm 0,00$ & $05,92 \pm 2,94$ & $21,81 \pm 19,54$ \\
\hline $54 \mathrm{~h}$ & $\mathrm{NF}$ & $13,64 \pm 0,00$ & $20,45 \pm 3,21$ \\
\hline $72 \mathrm{~h}$ & $\mathrm{NF}$ & $06,31 \pm 1,61$ & $34,57 \pm 0,13$ \\
\hline \multicolumn{4}{l}{ NF: Não formou emulsão }
\end{tabular}

Ensaio realizado em Meio Mineral (MM) sem adição de solução de micronutrientes com o microrganismo Bacillus subtilis Jag248: como mostra a Figura 4 (A) observou-se nessas condições maior concentração de surfactina e crescimento celular quando comparado ao ensaio suco de Caju Clarificado (CAJC) $+\left(\mathrm{NH}_{4}\right)_{2} \mathrm{SO}_{4}$ apresentando concentração de biomassa de 1,55 \pm 0,01 g/L após 20 horas de ensaio e logo mantendo-se na fase estacionária. A produção de surfactina chegou a atingir concentrações de 161,41 \pm 0,01 mg/L no decorrer de $72 \mathrm{~h}$ de ensaio, a glicose foi totalmente consumida nas primeiras 20 horas de fermentação e o pH manteve-se 
acima de 6,0. Observou-se redução da tensão superficial de 51,0 $\pm 0,0 \mathrm{dina} / \mathrm{cm}$ (branco) para $28,65 \pm 0,16 \mathrm{dina} / \mathrm{cm}$ após dez horas de ensaio e permanecendo nessa faixa em todas as amostras avaliadas até 72 horas.
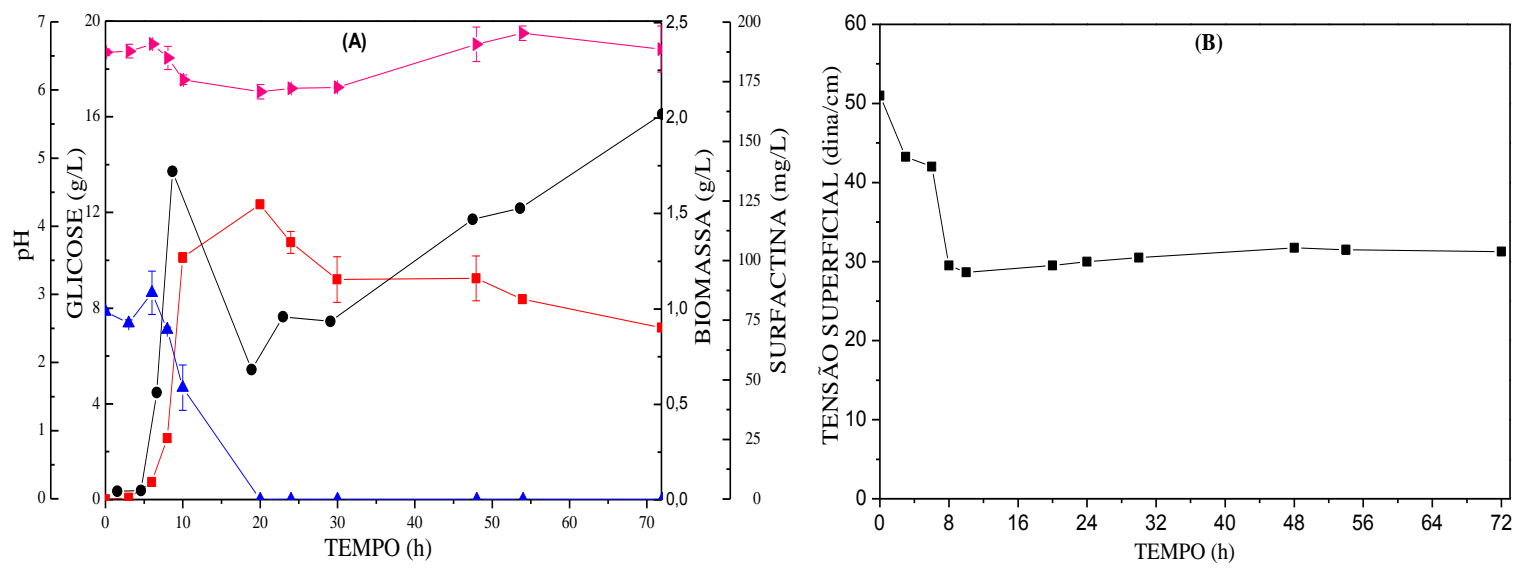

Figura 4 - (A) Perfil do crescimento celular (biomassa), consumo de substrato, produção de surfactina e pH em função do tempo para Bacillus subtilis Jag248, sob rotação de $180 \mathrm{rpm}$, temperatura de $30^{\circ} \mathrm{C}$ em Meio Mineral (MM) sem Solução Micronutrientes: ( $\square$ ) Biomassa, ( $($ ) pH, (•) Surfactina, ( $\boldsymbol{\Delta}$ ) Glicose; (B) Redução da Tensão superficial (ロ) em função do tempo para Bacillus subtilis Jag248 em Meio Mineral (MM) sem Solução Micronutrientes.

Avaliou-se ainda a capacidade emulsionante do biossurfactante produzido. A Tabela 3 mostra os resultados de Índice de Emulsificação para o ensaio realizado utilizando Bacillus subtilis Jag248 em Meio Mineral (MM) sem adição de Solução Micronutrientes.

Tabela 3 - Resultados obtidos de Índice de Emulsificação para o ensaio realizado utilizando Bacillus subtilis Jag248 em Meio Mineral (MM) sem adição de Solução Micronutrientes.

\begin{tabular}{c|c|c|c}
\hline AMOSTRA & ÓLEO DE SOJA & QUEROSENE & N-HEXADECANO \\
\hline $30 \mathrm{~h}$ & $57,00 \pm 11,41$ & $07,02 \pm 0,17$ & $09,64 \pm 1,00$ \\
\hline $48 \mathrm{~h}$ & $53,16 \pm 14,60$ & $16,00 \pm 5,66$ & $14,82 \pm 0,25$ \\
\hline $54 \mathrm{~h}$ & $52,00 \pm 2,83$ & $18,00 \pm 2,83$ & $13,89 \pm 3,93$ \\
\hline $72 \mathrm{~h}$ & $43,72 \pm 11,32$ & $56,26 \pm 11,68$ & $54,35 \pm 14,63$ \\
\hline
\end{tabular}

\section{CONCLUSÕES}

De acordo com os resultados obtidos, verificou-se que o microrganismo Bacillus subtilis Jag248 apresentou-se como potencial produtor de biossurfactantes em meio mineral, produzindo em torno de 161,41 $\pm 0,01 \mathrm{mg} / \mathrm{L}$ de biossurfactante com 72 horas de fermentação. Com o microrganismo Bacillus subtilis Jag249 verificou-se que o mesmo havia perdido seu poder de produção, pois não reduzia a tensão superficial do meio no decorrer do ensaio fermentativo. Com 
os resultados obtidos com a cepa Jag248, mais estudos serão realizados para otimizar a produção a fim de alcançar maiores concentrações do bioproduto obtido.

\section{REFERÊECIAS}

ABOUSEOUD, M.; MAACHI, R.; AMRANE, A.; BOUDERGUA, S.; NABI, A. Evaluation of different carbon and nitrogen sources in production of biosurfactant by Pseudomonas fluorescens. Desalination., v. 223 (1-3), p. 143-151, 2008.

BANAT, I. M.; MAKKAR, R. S.; CAMEOTRA, S. S. Potential commercial applications of microbial surfactants. Appl. Microbiol. Biotechnol., v. 53, p. 495-508, 2000.

BARRETO, R. V. G. Prospecção ambiental de microrganismos e genes envolvidos com a produção de biossurfactantes. Tese (Doutorado em Biotecnologia - RENORBIO) Universidade Estadual do Ceará, Conselho Nacional de Desenvolvimento Científico e Tecnológico, 2011.

COOPER, D. G.; GOLDENBERG, B. G. Surface-active agents from two Bacillus species. Applied and Environmental Microbiology, v. 53, n. 2, p. 224-229, 1987.

COSTA, S. G. V. A. O., NITSCHKE, M., HADDAD, R., EBERLIN, M. N., CONTIERO, J. Production of Pseudomonas aeruginosa LB1 rhamnolipids following growth on brazilian native oils. Process Biochemistry, v. 41, p. 483 - 488, 2006.

FRANZETTI, A.; TAMBURINI, E.; BANAT, I.M. Application of biological surface active compounds in remediation technologies. In: Sen, R. (Ed.), Biosurfactants: advances in Experimental Medicine and Biology, vol. 672. Springer-Verlag, Berlin Heidelberg, 14 p., 121-134, 2010.

MAKKAR, R. S.; CAMEOTRA, S.S. Biosurfactant production by a thermophilic Bacillus subtilis strain. Journal of Industrial Microbiology and Biotechnology, v. 18: p. 37 - 42, 1997.

MÓRAN, A. C.; OLIVEIRA, N.; COMMENDATORE, M.; ESTEVES, J. L.; SINERIZ, F. Enhancement of hydrocarbon waste biodegradation by addition of a biosurfactant from Bacillus subtilis O9. Biodegradation, v. 11 (1), p. 65 - 71, 2000.

OLIVEIRA, D. W. F.; FRANÇA, I. W. L.; FELIX, A. K. N.; MARTINS, J. J. L.; GIRO, M. E. A.; MELO, V. M. M.; GONÇALVES, L. R. B. Kinetic study of biosurfactant production by Bacillus subtilis LAMI005 grown in clarified cashew apple juice. Colloids and Surfaces B: Biointerfaces, V. 101, P. 34-43, 2013.

PERFUMO, A.; SMYTH, T. J. P.; MARCHANT, R.; BANAT, I. M.. Production and Roles of Biosurfactants and Bioemulsifiers in Accessing Hydrophobic Substrates. K. N. Timmis (ed.), Handbook of Hydrocarbon and Lipid Microbiology, Springer-Verlag Berlin Heidelberg, 09 p., 1502-1510, 2010.

PINTO, M. P.; MARTINS, R. G.; COSTA, J. A. V. Avaliação Cinética da Produção de Biossurfactantes Bacterianos. Quim. Nova, Vol. 32, No. 8, 2104-2108, 2009. 